\section{Effect of Blood Contamination on The Push-Out Bond Strength of Calcium Silicate Cements}

Flavia Kolling Marquezan ${ }^{1}$, Patricia Maria Poli Kopper ${ }^{1}$, Angela Isabel dos Santos Dullius², Diego Machado Ardenghi3 ${ }^{3}$ Renata Grazziotin-Soares ${ }^{3}$
'Department of Conservative Dentistry, UFRGS - Universidade Federal do Rio Grande do Sul, Porto Alegre, RS, Brazil ${ }^{2}$ Department of Statistics, UFSM - Universidade Federal de Santa Maria, Santa Maria, RS, Brazil ${ }^{3}$ College of Dentistry, University of Saskatchewan, SK, Canada

Correspondence: Renata GrazziotinSoares, 307-105 Wiggins Rd, Saskatoon SK S7N 5E4 Canada. e-mail : renata.grazziotin@usask.ca

Key Words: blood contamination, mineral trioxide aggregate, push out bond strength
This study investigated the effect of blood-contamination on the push-out bond strength of Biodentine ${ }^{T M}$ (BD) and MTA Angelus ${ }^{\circledast}$ (MTA-A) to root dentin over time. Twenty-five teeth were sectioned horizontally to obtain 120 root slices. The lumens were filled with MTA-A or BD: 60 for each cement (30 uncontaminated and 30 blood contaminated). Push out bond strength to dentin was assessed at $24 \mathrm{~h}(\mathrm{n}=10), 7$ days $(n=10)$ and 28 days $(n=10)$. Failure modes were classified as: cohesive, adhesive or mixed failure. Two-way ANOVA was used to investigate the interaction between blood contamination vs. hydration period. Mann Whitney test compared different materials in each period, and it also compared the contaminated versus uncontaminated material for each period. Friedman, followed by Dunn's test, compared periods of hydration for each material, regardless of blood contamination. Failure modes were reported descriptively. The interaction hydration period vs. blood contamination was highly significant for MTA-A $(\mathrm{P}=0.001)$ and it was not significant for BD $(\mathrm{P}=0.474)$. There were no differences between bond strength of uncontaminated and contaminated $\mathrm{BD}$ in any of the periods. Bond strength of uncontaminated MTA-A increased at each time of hydration; but it remained stable over time for blood-contaminated samples. $B D$ had higher bond strength than MTA-A in all periods of hydration. Cohesive failure predominated. Only for MTA-A, the over time bond strength to dentin was affected by blood contamination.

\section{Introduction}

It is of vital importance that calcium silicate cements resist dislodgment to guarantee the predictability and success of a dental treatment. In addition, the material bond strength to dentin should be enough to support the planned restorative procedures and the patient's masticatory forces. Although calcium silicate cements are hydrophilic $(1,2)$, blood contamination such as the ones that happen when those cements are used in pulp revascularization therapy $(3,4)$ can reduce the bond strength of the cement to dentin over time, leading to the cement degradation and failure (5).

Some studies have demonstrated the inhibition of the hydration process and the compromising of the physical properties in samples of mineral trioxide aggregate contaminated with blood $(6,7)$. In contrast, other authors showed that blood contamination had no effect on the bond strength of Biodentine ${ }^{\mathrm{TM}}$ - irrespectively of the hydration period (8); or that blood contamination increased the bond strength of ProRoot WMTA (9).

Currently, there is little information regarding the over time effects of blood contamination on the bond strength to dentin using contemporary calcium silicate cements, such as Biodentine ${ }^{\mathrm{TM}}$. and MTA Angelus (8). As a result, the use of bioactive cements in intimate contact with blood may not be well understood.

Therefore, considering the clinical relevance of avoiding cement dislocation when it is used adjacent to blood, and the considerable importance to predict the results of the dental treatment over time, the purpose of this in vitro study was: to investigate the effect of blood-contamination on the bond strength of Biodentine ${ }^{\mathrm{TM}}$ (BD; Septodont, Saint Maur des Fossés, France) and MTA Angelus ${ }^{\oplus}$ (MTA-A; Angelus Dental Industry Products $S / A$ ) to root dentin at three different moments after hydration $(24 h, 7$ days and 28 days), through push-out bond strength tests observing its failure mode (adhesive, cohesive or mixed). The null hypothesis is that blood contamination does not affect the cement push-out bond strength over time. Thus, it was expected that the interaction hydration period vs. blood-contamination would not be significant for the push-out bond strength values between the contaminated and uncontaminated cements.

\section{Material and Methods}

\section{Specimen Preparation}

This study was approved by the appropriated university 
ethics review committee. Twenty-five extracted singlerooted human teeth with straight roots and no root canal treatment were selected. Teeth were disinfected with sodium hypochlorite $5.25 \%$ for $30 \mathrm{~min}$ and stored in saline solution for up to one month before use. Midroot dentin was sectioned horizontally into slices with a thickness of $1.0 \mathrm{~mm}$ using a low-speed diamond saw driven by a cutting machine (Labcut 1010: Extec Corp., Enfield, CT, EUA) to obtain 120 root dentin slices, 60 specimens for each cement (30 uncontaminated and 30 blood contaminated), in the following experimental times: $24 h(n=10), 7$ days $(n=10)$, 28 days $(n=10)$. The lumens of the root slices were drilled with a \#5 Gates-Glidden bur (Dentsply Maillefer, Ballaigues, Switzerland) to obtain $1.3-\mathrm{mm}$ diameter standardized cavities. Then, the root slices were carefully rinsed with $2.5 \% \mathrm{NaOCl}$ for $15 \mathrm{~min}$ followed by 17\% EDTA for $3 \mathrm{~min}$ and further neutralized with distilled water. The prepared slices were randomized for MTA-A or BD. Groups were labeled according to the presence of contamination and the hydration period (debonding interval). MTA-A and BD were mixed according to their manufacture instructions and placed inside the lumens of the root slices. MTA-A was mixed using $1 \mathrm{~g}$ of powder and $0.33 \mathrm{~g}$ of distilled water, weighted in a precision scale. BD was mixed using the powder and liquid provided in the commercial packages using an amalgamator (AmalgaMix, Gnatus, Rio de Janeiro, RJ, Brazil) for $30 \mathrm{~s}$ and 4500 revolutions per minute.

For the blood contaminated specimens, before placing the cement into the root slice, the lumen of the dentin slice was filled with sheep blood agar (Labsul Produtos para Laboratorio, Porto Alegre, RS, Brazil), subsequently the blood excess was removed by aspirating it with a syringe leaving a coating of blood on the inner wall of the specimens. For all specimens, the excess of cement was carefully removed from the upper and lower part of the slices using small cotton pellets. This cleaning procedure aimed to have the cement adhered only to the inner dentin of the slices.

Aiming to produce a saturated humid atmosphere, the samples were placed between two moistened cotton pellets in sealed 1.5-mL Eppendorf tubes. For the blood contaminated samples, the cotton pellet located under the specimen was moistened with blood, and the upper cotton pellet was moistened with distilled water. For the uncontaminated specimens, both cotton pellets were moistened with distilled water. Samples were then incubated at $37^{\circ} \mathrm{C}, 95 \%-100 \%$ humidity for $24 \mathrm{~h}$, 7 days or 28 days.

\section{Push-Out Bond Strength Test}

The cement bond strength to dentin was assessed by push-out tests using a universal testing machine (DL-2000
Emic, São José dos Pinhais, PR, Brazil). To keep the dentin slice in place during the push-out test, a colorless acrylic resin disc (with $3 \mathrm{~cm}$-diameter and a central orifice) was manufactured and attached (using cyanoacrylate adhesive) to the outer side of the dentin slice.

The samples were placed on a metal slab with a central hole to allow free motion of the plunger. Loading was applied exerting a downward pressure on the cement surface using a 0.85 -mm-diameter stainless steel cylindrical plunger at a crosshead speed of $1 \mathrm{~mm} / \mathrm{min}$ until a bond failure occurred $(10,11)$. To calculate the bond strength in megapascal (MPa), the bond strength at failure was recorded in newtons $(\mathrm{N})$ and divided by the adhesion area $\left(\mathrm{mm}^{2}\right)$ of the cement filling. The bonding area was calculated using the formula $2 \pi r \times h$, where $\pi$ is the constant $3.14, r$ is the root canal radius, and $\mathrm{h}$ is the thickness of the root slice in millimeters (12).

\section{Failure Modes Assessment}

Slices were then examined under a stereomicroscope (Discovery V20, Carl Zeiss, Germany) at 15x magnification to determine the modes of the bond failure. The images were codified using letters and numbers and stored in JPEG files. Two examiners independently evaluated the images twice with an interval of 15 days between each evaluation. The observed failure modes were: i) adhesive, a failure between the cement and dentin interface; ii) cohesive, a failure within the cement and iii) mixed failure mode.

\section{Data Analysis}

Two separated statistical analysis were performed for bond strength data, as follow: $1^{\circ}$ ) For each cement (MTA-A and BD), data normality verification (equality of variances) was performed using Levene's test. Only for MTA-A, the dependent variable (push-out bond strength) presented non-normal distribution $(p=0.036)$. Then, data transformation (square root) was performed. Subsequently, two-way ANOVA was used to analyze if the bond strength was influenced by two factors (contamination and time of hydration). Significance level was set at 5\%. $2^{\circ}$ ) Multiple comparisons were performed with non-normal distribution tests, as the normality of samples could not be proven. Mann Whitney's test was used to compare MTA-A and $\mathrm{BD}$ bond strength in each hydration period, regardless of blood contamination; and, also, to compare bond strength of blood contaminated and uncontaminated material in each hydration period. Friedman's test, followed by Dunn's test was used to compare bond strength between periods of hydration for each material, regardless of blood contamination. Significance level was set at $5 \%$.

Data from stereomicroscope assessment were analyzed 
by Kendall's tau-b $\left(\tau_{b}\right)$ correlation coefficient to measure intra and inter-examiner agreement regarding the classification of the images in adhesive, cohesive and mixed failure mode [excellent intra-examiner $(\mathrm{RGS}=1.0$ and $F K M=0.91)$ and a very good inter-examiner $(0.81)$ agreement]. Findings from failure mode analysis were reported descriptively (frequency). All statistical analyses were performed using the Statistical Package for the Social Sciences (SPSS) version 22.0 (SPSS Inc., Chicago, IL, USA).

\section{Results}

Figure 1 shows the mean values of bond strength (MPa) according to hydration period for MTA-A and BD blood contaminated and uncontaminated samples. Two-way ANOVA showed that the interaction between the hydration period and blood contamination was significant for MTA-A $(p=0.001)$ and not significant for BD $(p=0.474)$. For both

Table 1. Push-out bond strength values (median, maximum and minimum) (Mpa) for uncontaminated and blood contaminated samples of MTA Angelus (MTA) and Biodentine TM (BD), at $24 \mathrm{~h}, 7$ days and 28 days after hydration.

\begin{tabular}{lccc}
\hline Contamination & Hydration period & MTA-Angelus & Biodentine $^{\mathrm{TM}}$ \\
\hline \multirow{2}{*}{ Uncontaminated } & $24 \mathrm{~h}$ & $0.34(1.31-0.21) \mathrm{Aa}^{*}$ & $8.89(16.31-3.59) \mathrm{Ab}$ \\
& 7 days & $1.40(5.84-0.46) \mathrm{Ba}$ & $4.06(10.11-0.96) \mathrm{Ab}$ \\
& 28 days & $3.46(6.59-0.53) \mathrm{Ca}$ & $5.10(15.90-2.15) \mathrm{Ab}$ \\
\hline \multirow{2}{*}{$\begin{array}{l}\text { Blood } \\
\text { contaminated }\end{array}$} & $24 \mathrm{~h}$ & $1.84(4.17-0.55) \mathrm{Aa}^{*}$ & $12.29(15.79-5.12) \mathrm{Ab}$ \\
& 7 days & $1.69(7.66-0.39) \mathrm{Aa}$ & $7.59(32.31-3.01) \mathrm{Bb}$ \\
\hline
\end{tabular}

Different capital letters represent significant differences on bond strength between hydration period for each material, regardless blood contamination (Friedman's and Dunn's tests; $p<0.05$ ). Different lower case letters represent significant differences between MTA-A and BD bond strength on each hydration period, regardless of blood contamination (Mann Whitney test; $p<0.05$ ). Asterisk represents significant differences on bond strength for each hydration period between blood contaminated and uncontaminated material (Mann Whitney test; $p<0.05$ ). materials, contamination by itself did not influence the bond strength ( $p>0.05$ ). However, the periods of hydration affected the bond strength, regardless of the blood contamination ( $p=0.010$ for MTA-A; $p=0.012$ for $B D$ ).

Table 1 shows the following information:a) comparison of bond strength over time, for each material, b) comparison of bond strength between materials for each hydration period and c) comparison of bond strength for each hydration period between blood contaminated and uncontaminated material.

Regarding the uncontaminated BD samples, the bond strength was similar over time ( $p>0.05)$. For the bloodcontaminated BD samples, the bond strength at $24 \mathrm{~h}$ was higher than at 7 days $(p=0.023)$ and 28 days $(p=0.001)$. $0 n$ the other hand, when comparing bond strength of blood contaminated and uncontaminated $\mathrm{BD}$ samples, there were no differences between them in any of the times ( $p>0.05)$.

As far as the uncontaminated MTA-A samples are concerned, the bond strength increased at each time of hydration; and for blood-contaminated samples the bond strength remained stable over time. When comparing bond strength of blood contaminated and uncontaminated MTA-A samples, there was a significant difference between them only at $24 \mathrm{~h}(\mathrm{p}=0.0004)$.

When comparing those two different cements, MannWhitney test showed that $B D$ had higher bond strength than MTA-A, regardless of the contamination, in all periods of hydration $(p<0.05)$.
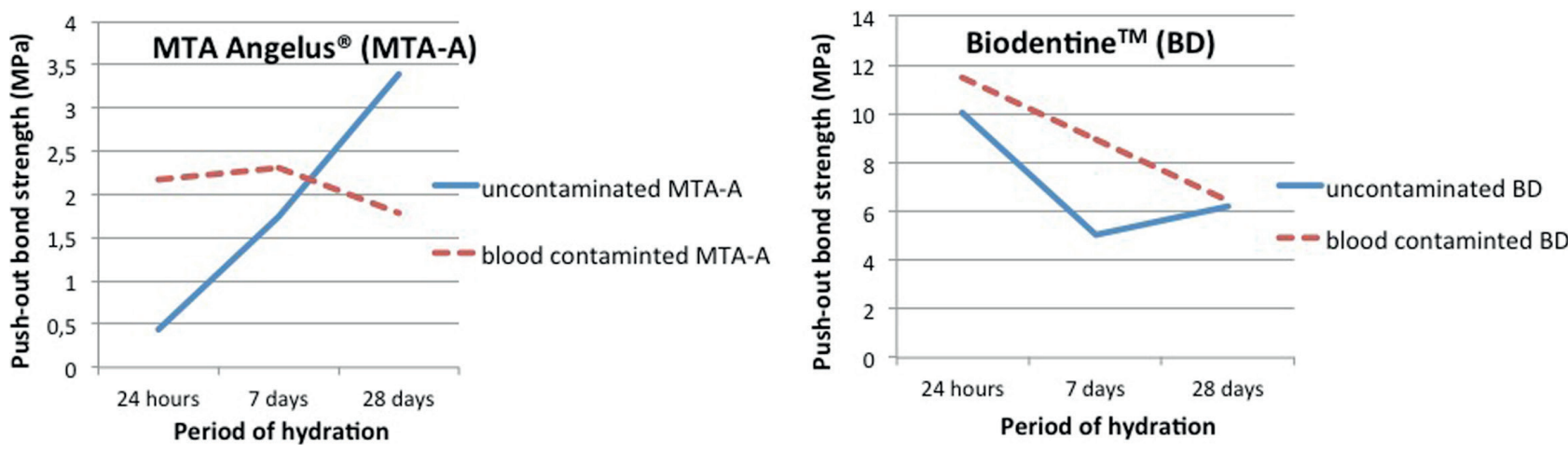

Figure 1. Mean values of push-out bond strength (MPa) according to hydration period for MTA-A and BD blood contaminated and uncontaminated samples. 
Table 2 shows the results of failure mode analyses. For all situations, the cohesive failure mode was predominant. Figure 2 shows examples of failure modes.

\section{Discussion}

Blood contamination affected the MTA-A bond strength to dentin over time. However, the interaction hydration period vs. blood contamination was not significant for the push-out bond strength of BD. Therefore, the null hypothesis of this study was accepted only for the BD.

According to the literature the increase in bond strength over time for the uncontaminated MTA might be a result of its the improvement of hydration as time passes $(13,14)$. Regarding the blood contaminated MTA-A samples, although they presented higher values of bond strength when comparing to uncontaminated samples in the first week (statistically significant at $24 \mathrm{~h}$ ), bond strength remained relatively stable on different times of hydration (there was no statistical difference among the
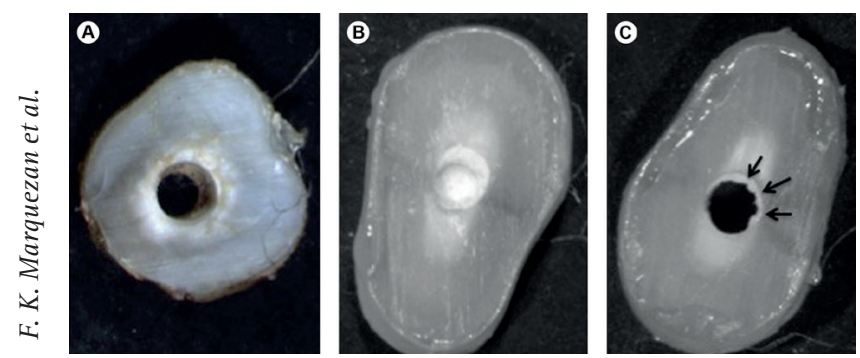

Figure 2. Examples of failure modes: (A) adhesive, a failure between the cement and the dentin; (B) cohesive, a failure within the cement; and (C) mixed failure, a failure that presents cohesive and adhesive failures in the same sample. The arrows indicate a cohesive failure and the part without arrow indicates an adhesive failure. three experimental times). That is, in the beginning of hydration, it seems that blood could have a positive effect on MTA-A bond strength to dentin. However, as the bond strength of the blood contaminated MTA-A remained stable over time, it indicates that the hydration process had been impaired. This conclusion is supported by the comparison of blood contaminated MTA-A samples with the uncontaminated samples.

A possible explanation is that, initially, blood enhanced the humid conditions of the environment, leading to a rapid beginning of the hydration process for the MTA-A. However, as time passed, blood had a mechanical and chemical interference on the MTA-A bond strength to the dentin, preventing the over-time improvement of the bond strength. Mechanically, the blood components (different cells and proteins) could have partially blocked the dentinal tubules and the gaps existent on the cementdentin interface (9). This blockage could have prevented the growing of the hydroxyapatite crystals that should fill and connect the spaces between the cement and the dentin, consequently, impairing the bond strength of the cement. In addition, blood might become chemically incorporated into the cement, interfering with the MTA-A hydration process (7). The compounds of blood might act as fillers in the hydrated phase of calcium silicate (C-S-H gel), forming a structure comprised of C-S-H-blood, similarly to what occurs with the radiopacifier bismuth oxide during hydration of MTA-A $(13,15,16)$. This, would affect the $\mathrm{Ca}[\mathrm{OH}]_{2}$ precipitation, interfering with the bioactivity of the hydrated material and, with its ability to improve retention over time.

For $B D$, the high bond strength in the beginning of the hydration process has already been explained in the literature. BD powder contains calcium carbonate that acts as a nucleation site for $\mathrm{C}-\mathrm{S}-\mathrm{H}$, reducing the induction period and leading to an initial setting a few minutes after mixing. Therefore, it is expected a rapid mechanical strength. Additionally, the liquid of BD is a calcium chloride solution, a solution that can be considered a setting time accelerator (14). Thus, the considerable speed of the hydration process might have prevailed the blood interference on the BD-dentin interface.

Overall, the majority of the failures were cohesive, except for the blood contaminated BD 
where they were mixed. An interesting finding observed in both blood contaminated cements (MTA-A and BD) was an over time decrease in the number of cohesive failures (cohesive failures turned into adhesive and mixed), this could mean a decrease in bonding strength over time $(17,18)$. Specifically regarding blood contaminated MTA-A, although bond strength values did not have statistical difference over time, the decrease of cohesive failures over time could demonstrate a trend of a progressing poor hydration process. This trend could be confirmed in further studies with longer periods of bond strength assessments.

This study used defibrinated sheep blood to contaminate samples to cope with ethical considerations and biohazard issues that are present when human blood is obtained by phlebotomy. Additionally, if this study had used human blood, we would need the blood added to an anticoagulant agent, to impede the settlement of slurries (6). Even though in vitro studies in endodontics do not usually choose animal blood to contaminate samples (19), the use of sheep blood is widely used in many other fields of research $(20,21)$, because of its similarities to human blood (22). Another point of relevance is that the push-out test has its own limitations, as any other mechanical test. The literature has already showed that several factors can affect the pushout results such as the plunger diameters, the specimen thickness, the elastic moduli of the fillers etc. (23). Despite that, this present study chose the push-out test because it has been broadly used to determine the bond strength of endodontic materials $(8-12,18,24)$ and because it is able to simulate a clinical situation where the cement is placed inside the canal lumen. In addition, in dentistry, the micropush-out test may be considered more reliable than the microtensile test in the bond strength investigation, due to the uniform stress concentration and adhesive failure pattern (25). Furthermore, slices from the midroot dentin (and not from the apical third) were chosen to test the cements bond strength because one of the clinical indications of a calcium silicate cement is to be used as a material for pulp revascularization therapy, which is usually performed on cervical and/or medium root thirds (26).

The non-improvement of bond strength over time for blood contaminated MTA-A means that blood affected the material bonding. Although longer periods of hydration (more than 28 days) were not evaluated in this study, the Figure 1 and the failure mode analysis suggested that blood could progressively reduce MTA-A bond strength. Based on this, it could be speculated that the use of a barrier (such as calcium hydroxide powder) between the tissue and the MTA-A could minimize the contact of the material with blood, consequently, reducing the chance of material dislocation. This hypothesis was beyond the scope of this study, but it reminds the need for further studies to verify the possibility of using a barrier.

It is possible that the reduction of BD bond strength over time might not be clinically relevant, since the values of bond strength for BD were much higher than for MTA-A, which is a bioactive cement well-established for clinical use. Contemporary long-term follow-up clinical studies have shown the potential of BD to be used in contact with blood $(27,28)$. The superior bond of BD over MTA-A was previously stated in the literature $(10,17)$ and it is attributed to a higher biomineralization ability of $\mathrm{BD}$, leading to a better bond to dentin (29).

Based on the present findings and within the limitations of this in vitro study it was concluded that blood contamination affected the push-out bond strength of MTA-A over time, when compared to uncontaminated samples. Although MTA-A bonding was initially higher in contaminated samples, the bond strength did not increase over time as it occurred for uncontaminated samples. On the other hand, push-out bond strength of BD was not affected by blood contamination over time. BD had bond strength reduced over time, regardless the contamination. Moreover, BD presented higher push-out bond strength than MTA-A, regardless the contamination, in all periods of hydration.

\section{Resumo}

Este estudo investigou o efeito da contaminação sanguinea na resistência de união do Biodentine ${ }^{T M}$ (BD) e do MTA Angelus ${ }^{\circledast}$ (MTA-A) à dentina, em diferentes períodos. Vinte e cinco dentes foram seccionados para obter 120 fatias de dentina. Os lúmens das fatias foram preenchidos com MTA-A ou $\mathrm{BD}: 60$ para cada cimento (30 não-contaminados e 30 contaminados com sangue). A resistência de união à dentina foi medida por teste push-out em 24 horas $(n=10), 7$ dias $(n=10)$ e 28 dias $(n=10)$. Os tipos de falha foram classificados como: falha coesiva, adesiva ou mista. Two-way ANOVA foi usado para investigar a interação entre contaminação sanguínea vs. periodo de hidratação. 0 teste de Mann Whitney comparou os diferentes materiais em cada período, e comparou as amostras contaminadas e não contaminadas de cada material em cada tempo. 0 teste de Friedman, seguido pelo teste de Dunn, comparou os períodos de hidratação de cada material, independentemente da contaminação. A análise estatística mostrou a interação entre contaminação sanguínea vs. periodo de hidratação. Os tipos de falha foram reportados de maneira descritiva. A interação entre contaminação sanguínea vs. periodo de hidratação foi altamente significativa para o MTA-A $(P=0,001)$, e não foi significativa para o $B D(P=0,474)$. Não houve diferenças entre a resistência de união entre o BD contaminado e não-contaminado independente do período. A resistência de união do MTA-A não-contaminado aumentou a cada tempo de hidratação; mas, permaneceu estável ao longo do tempo para as amostras contaminadas com sangue. BD obteve maior resistência de união que o MTA-A em todos os períodos de hidratação. Falhas coesivas predominaram. A contaminação ao longo do tempo influenciou a resistência de união no grupo MTA-A.

\section{References}

1. Parirokh M, Torabinejad M. Mineral trioxide aggregate: a comprehensive literature review-Part III: Clinical applications, drawbacks, and mechanism of action. J Endod 2010;36:400-413.

2. Prati C, Gandolfi MG. Calcium silicate bioactive cements: Biological perspectives and clinical applications. Dent Mater 2015;31:351-370. 
3. Banchs F, Trope M. Revascularization of immature permanent teeth with apical periodontitis: new treatment protocol? J Endod 2004;30:196-200.

4. Chen MY, Chen KL, Chen CA, Tayebaty F, Rosenberg PA, Lin LM. Responses of immature permanent teeth with infected necrotic pulp tissue and apical periodontitis/abscess to revascularization procedures. Int Endod J 2011;45:294-305.

5. Nekoofar MH, Stone DF, Dummer PM. The effect of blood contamination on the compressive strength and surface microstructure of mineral trioxide aggregate. Int Endod J 2010;43:782-791.

6. Nekoofar MH, Oloomi K, Sheykhrezae MS, Tabor R, Stone DF, Dummer PM. An evaluation of the effect of blood and human serum on the surface microhardness and surface microstructure of mineral trioxide aggregate. Int Endod J 2010;43:849-858.

7. Nekoofar MH, Davies TE, Stone D, Basturk FB, Dummer PM. Microstructure and chemical analysis of blood-contaminated mineral trioxide aggregate. Int Endod J 2011;44:1011-1018.

8. Aggarwal V, Singla M, Miglani S, Kohli S. Comparative evaluation of push-out bond strength of ProRoot MTA, Biodentine, and MTA Plus in furcation perforation repair. J Conserv Dent 2013;16:462-465.

9. Rahimi S, Ghasemi N, Shahi S et al. Effect of blood contamination on the retention characteristics of two endodontic biomaterials in simulated furcation perforations. J Endod 2013;39:697-700.

10. Guneser MB, Akbulut MB, Eldeniz AU. Effect of various endodontic irrigants on the push out bond strength of biodentine and conventional root perforation repair materials J Endod 2013;39:380-384.

11. Nagas E, Cehreli ZC, Uyanik MO, Vallittu PK, Lassila LV. Effect of several intracanal medicaments on the push-out bond strength of ProRoot MTA and Biodentine. Int Endod J 2016;49:184-188.

12. Saghiri MA, Shokouhinejad N, Lotfi M, Aminsobhani M, Saghiri AM. Push-out bond strength of mineral trioxide aggregate in the presence of alkaline pH. J Endod 2010;36:1856-1859.

13. Camilleri J. Characterization of hydration products of mineral trioxide aggregate. Int Endod J 2008;41:408-417.

14. Camilleri J, Sorrentino F, Damidot D. Investigation of the hydration and bioactivity of radiopacified tricalcium silicate cement, Biodentine and MTA Angelus. Dent Mater 2013;29:580-593.

15. Camilleri J. Evaluation of the physical properties of an endodontic Portland cement incorporating alternative radiopacifiers used as rootend filling material. Int Endod J 2010;43:231-240.

16. Grazziotin-Soares R, Nekoofar MH, Davies TE et al. Effect of bismuth oxide on white mineral trioxide aggregate: chemical characterization and physical properties. Int Endod J 2014;47:520-533.
17. Thompson Jl, Gregson PJ, Revell PA. Analysis of push-out test data based on interfacial fracture energy. J Mater Sci Mater Med 1999;10:863-868.

18. Assmann E, Scarparo RK, Böttcher DE, Grecca FS. Dentin bond strength of two mineral trioxide aggregate-based and one epoxy resin-based sealers. J Endod 2012;38:219-221.

19. Song $M$, Yue $W$, Kim S et al. The effect of human blood on the setting and surface micro-hardness of calcium silicate cements. Clin Oral Investig 2016;20:1997-2005.

20. Satzke C, Seduadua A, Chandra R, Carapetis JR, Mulholland EK, Russell FM. Comparison of citrated human blood, citrated sheep blood, and defibrinated sheep blood Mueller Hinton agar preparations for antimicrobial susceptibility testing of Streptococcus pneumoniae isolates. J Clin Microbiol 2010;48:3770-3772.

21. Landa-Solis C, Olivos-Meza A, Ortega-Sánchez C et al. Comparison of the Homology and Functionality of the Pluripotent Stem Cells derived from the Human and Sheep Peripheral Mobilized Blood. Tissue Engineering Part A 2014;20(140) S129-S129 (P-718).

22. Amin TM, Sirs JA. The blood rheology of man and various animal species. Q J Exp Physiol 1985;70:37-49.

23. Chen WP, Chen YY, Huang SH, Lin CP. Limitations of push-out test in bond strength measurement. J Endod. 2013 Feb;39:283-287.

24. Dawood AE, Manton DJ, Parashos P, Wong RH, Palamara JE, Reynolds EC. Push-out bond strength of CPP-ACP-modified calcium silicatebased cements. Dent Mater J 2015;34:490-494.

25. Campos RE, Santos Filho PCF, de 0 Júnior OB, Ambrosano GMB, Pereira CA. Comparative evaluation of 3 microbond strength tests using 4 adhesive systems: Mechanical, finite element, and failure analysis. J Prosthet Dent 2018;119:166-174.

26. Galler KM. Clinical procedures for revitalization: current knowledge and considerations. Int Endod J. 2016;49:926-936.

27. El Meligy OA, Allazzam S, Alamoudi NM. Comparison between biodentine and formocresol for pulpotomy of primary teeth: A randomized clinical trial. Quintessence Int 2016;47:571-580.

28. Rajasekharan $S$, Martens $L$, Vandenbulcke J, Jacquet $W$, Bottenberg $P$, Cauwels R. Efficacy of three different pulpotomy agents in primary molars - A randomized control trial. Int Endod J 2017;50:215-228.

29. Han L, Okiji T. Bioactivity evaluation of three calcium silicate-based endodontic materials. Int Endod J 2013;46:808-814.

Received August 28, 2017 Accepted December, 14, 2017 